\title{
Substructure of Thin Foil (225) Ferrous Martensites
}

\author{
By R. Oshima* and C. M. Wayman**
}

\begin{abstract}
The substructure of thin foil martensite formed below room temperature was studied in $\mathrm{Fe}$ $6 \mathrm{Mn}-1 \mathrm{C}, \mathrm{Fe}-5.5 \mathrm{Mn}-1 \mathrm{C}, \mathrm{Fe}-3 \mathrm{Mn}-3 \mathrm{Cr}-1 \mathrm{C}$ and $\mathrm{Fe}-8 \mathrm{Cr}-1 \mathrm{C}$ steels using transmission electron microscopy and diffraction. In the thin foils, as with bulk materials, the martensite habit plane in the above alloys was found to be near $\{225\}$. Even though constraints are expected to be relaxed for thin foils (two-dimensional transformations) the observed substructure was found to be highly complex. Substantial evidence for accommodation distortion in thin foils was obtained.

Several morphologies of $\{112\}_{b}$ transformation twins, and $\{011\}_{b}$ and $\{123\}_{b}$ stacking faults were observed, in addition to dislocations. Upon examining the crystallography of $\{112\}_{b}$ twins in some detail, it was found that the previously reported deviation of the twin traces from \{112\} could arise from an incorrect assessment of the twin plane trace; the present work shows the long traces lying in the specimen plane are not necessarily twin plane traces.

Two types of twin-stacking fault interactions were observed. In one case, stacking faults which appear to be inherited from the austenite place crystallographic restrictions on the $\{112\}$ twins. Only those twin variants form whose twinning direction lies in the fault plane. In the other type of interaction, post-transformation accommodation distortion appears to occur by the activation of only those $\{110\}$ and $\{123\}$ fault variants which can penetrate both orientations of the $\{112\}$ twins without suffering deviation.
\end{abstract}

(Received May 27, 1974)

\section{Introduction}

Following the introduction of the phenomenological crystallographic theory of the martensite transformation ${ }^{(1) \sim(3)}$ there have been many investigations of crystallographic features of these transformations. It is generally agreed $^{(4)}$ that for ferrous alloys and steels good agreement between theory and experiment holds only for the $\{3,10,15\}_{f}^{\dagger}$ transformation. Other transformations, notably the $\{225\}_{f}$ transformation in carbon and certain alloy steels, have proved more difficult to understand in terms of the original crystallographic theory. Consequently other approaches involving double or multiple inhomogeneous shears have been introduced $^{(5)(6)}$ which result in better predictions in

* Department of Metallurgy and Mining Engineering, University of Illinois at UrbanaChampaign, Illinois. Present address: Faculty of Engineering Science, Osaka University, Toyonaka 560, Japan.

** Department of Metallurgy and Mining Engineering, University of Illinois at UrbanaChampaign, Urbana, Illinois 61801, U.S.A.

$\dagger$ Subscripts $f$ and $b$ refer respectively to the $f c c$ austenite and $b c c$ or $b c t$ martensite.

Trans. JIM general, but not complete satisfaction ${ }^{(4)}$.

Over the past ten years, a number of efforts, using principally transmission electron microscopy and diffraction (supplemented by X-ray analysis and optical metallography), to examine the substructure of martensites, particularly with regard to the inhomogeneous shear(s) of the theory have been made. Despite numerous investigations, there remains an overall incompleteness, in particular with reference to the $\{225\}_{f}$ transformation. $\mathrm{Fe}-\mathrm{C}^{(7)(8)}, \mathrm{Fe}-\mathrm{Cr}-$ $\mathrm{C}^{(7) \sim(9)}, \mathrm{Fe}-\mathrm{Cr}-\mathrm{Ni}^{(10)}$, and $\mathrm{Fe}-\mathrm{Mn}-\mathrm{Cr}-\mathrm{C}^{(11)}$ alloys have been studied in some detail. In $\mathrm{Fe}-\mathrm{C}$, $\mathrm{Fe}-\mathrm{Cr}-\mathrm{C}$ and $\mathrm{Fe}-\mathrm{Mn}-\mathrm{Cr}-\mathrm{C}\{225\}$ alloys, an $\{011\}_{b}$ planar inhomogeneity, in addition to $\{112\}_{b}$ twins and dislocations has been more or less consistently observed.

Generally, martensite plates exhibit a variety of internal defects such as twins, stacking faults, and dislocations. The observed defects can result from (1) the lattice invariant shear of the transformation per se and/or (2) the deformation of the growing martensite caused by constraints due to the surrounding matrix (i.e., a post-transformation effect). The distinction between these two categories is highly important in understanding the transformation mechanism, 
yet such a differentiation is virtually impossible for a number of martensites undergoing "bulk" transformation before thinning for electron microscopy observations. It was thus considered in the present work that the substructure in martensites formed in the thin film state might be simpler because of the two-dimensional nature of the transformation and the proportional absence of constraints. That is, thin film martensites may provide more direct information on defects intrinsic to the transformation per se. For the most part, transmission electron microscopy studies have involved specimens which were thinned after transformation in the bulk. However, there have been a few investigations of "thin film martensite" by Pitsch"(12) and Thomas et al. (13)

Possibly related to the substructure of $\{225\}$ martensites are the recent investigations in manganese and rhenium steels of martensite formed at low temperatures ${ }^{(14) \sim(16)}$, according to which the tetragonality is "abnormally" low. The low tetragonality, characteristic of sub-zero martensite, approaches the "normal" or expected value (considering the carbon content) on heating to room temperature. Lysak et al. ${ }^{(14)}$ suggested that the change in tetragonality is due to carbon atom redistribution during heating. They proposed that the abnormal bct martensite is generated via an intermediate hexagonal phase $^{(17)}$.

In the present investigation, thin austenite foils of $\mathrm{Fe}-\mathrm{Mn}-\mathrm{C}, \mathrm{Fe}-\mathrm{Cr}-\mathrm{C}$ and $\mathrm{Fe}-\mathrm{Mn}-\mathrm{Cr}-\mathrm{C}$ steels, all with $\mathbf{M}_{\mathbf{s}}$ temperatures below room temperature were transformed while cooling in the electron microscope (cold stage). The transformation was observed either in process or at low temperatures after its completion. Pretransformation lattice instabilities in austenite, unusual effects due to carbon atom clustering in freshly formed martensite (in Mn steels) and a variety of internal defects (substructure) have been observed. The first two of these will be discussed elsewhere, and a detailed presentation and analysis of the substructure will form the basis of the present paper.

\section{Procedure}

Four steels with different $M_{s}$ temperatures were selected for study: Fe-6Mn-1C $\left(\mathrm{M}_{\mathrm{s}} \approx\right.$ $\left.-120^{\circ} \mathrm{C}\right)^{\dagger}, \quad \mathrm{Fe}-5.5 \mathrm{Mn}-1 \mathrm{C} \quad\left(\mathrm{M}_{\mathrm{s}} \approx-100^{\circ} \mathrm{C}\right)$, $\mathrm{Fe}-3 \mathrm{Mn}-3 \mathrm{Cr}-1 \mathrm{C}\left(\mathrm{M}_{\mathrm{s}} \approx-80^{\circ} \mathrm{C}\right)$, and $\mathrm{Fe}-8 \mathrm{Cr}-$ $1 \mathrm{C}\left(\mathrm{M}_{\mathrm{s}} \approx-30^{\circ} \mathrm{C}\right)$. Disc specimens $3 \mathrm{~mm}$ diameter were punched from sheet stock of these materials (0.3-0.5 mm thick), austenitized in evacuated quartz capsules at $1200^{\circ} \mathrm{C}$ for $1 \mathrm{hr}$, and water quenched to room temperature. After an initial chemical polish in $\mathrm{H}_{2} \mathrm{O}_{2}$ $(30 \%)-\mathrm{HF}(1: 1)$ for the $\mathrm{Cr}$ steel and in $\mathrm{H}_{2} \mathrm{O}_{2}$ $(30 \%)-\mathrm{HF}-\mathrm{H}_{2} \mathrm{O}(73: 7: 20)$ for the others, all specimens were electro-thinned at $10^{\circ} \mathrm{C}$ in $\mathrm{H}_{3} \mathrm{PO}_{4}$ saturated with $\mathrm{CrO}_{3}$. Specimens were examined on a cooling stage of a Hitachi HU-11 electron microscope and also observed at room temperature using a Hitachi HU-12 microscope.

\section{Results and Discussion}

\section{General features}

Most martensite plates appeared to form instantly, and as a consequence, no information on the nature of the nucleating sites was obtained. At the final stage of transformation, some isothermal martensite plate thickening was observed to occur. The growth rate was on the order of $10^{3} \AA / \mathrm{sec}$. As a consequence of the transformation, specimens, in general, became heavily buckled which resulted in difficulties in analyzing the diffraction patterns and in making trace analyses. It was generally observed that growing martensite plates stopped short of the specimen edge, leaving a retained austenite region 1000-2000 $\AA$ in width. Even though constraints are less as a growing plate approaches the edge of a specimen, at first thought favoring the transformation, it should be noted that it would be difficult for plates to propagate in thin regions which are thinner than the transformation twins within the plates.

In a number of cases, the austenite-martensite interface was irregular and non-planar, as shown in Photo. 1. However, some plates were observed with a planar habit plane near $\{225\}_{f}$. An intermeshed structure between adjoining plates was also observed, as will be discussed later $^{(18)}$.

\footnotetext{
$\dagger$ Compositions are given in weight percentages.
} 


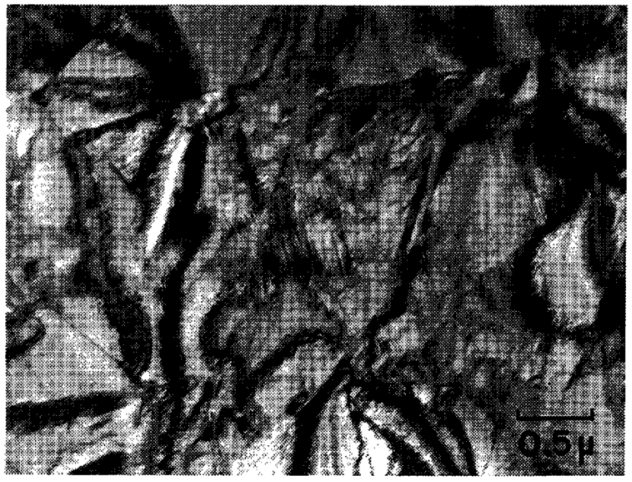

Photo. 1 Transmission electron micrograph showing martensite formed in thin foil of $\mathrm{Fe}-6 \mathrm{Mn}-1 \mathrm{C}$ alloy.

A variety of internal defects in plates were found, including long $\{112\}_{b}$ twins, finely segmented $\{112\}_{b}$ twins, $\{011\}_{b}$ and $\{123\}_{b}$ planar defects, and dislocations.

Prior to the formation of martensite, a peculiar "streaming" phenomenon was observed. This is considered to be a manifestation of a pretransformation lattice instability and will be considered in more detail later ${ }^{(19)}$.

Extra spots in the transmission diffraction patterns of freshly formed martensite in $\mathrm{Fe}-\mathrm{Mn}-\mathrm{C}$ and $\mathrm{Fe}-\mathrm{Mn}-\mathrm{Cr}-\mathrm{C}$ were observed and ascribed to a planar clustering of carbon atoms. These diffraction spots are thought to be related to the immobility of carbon atoms

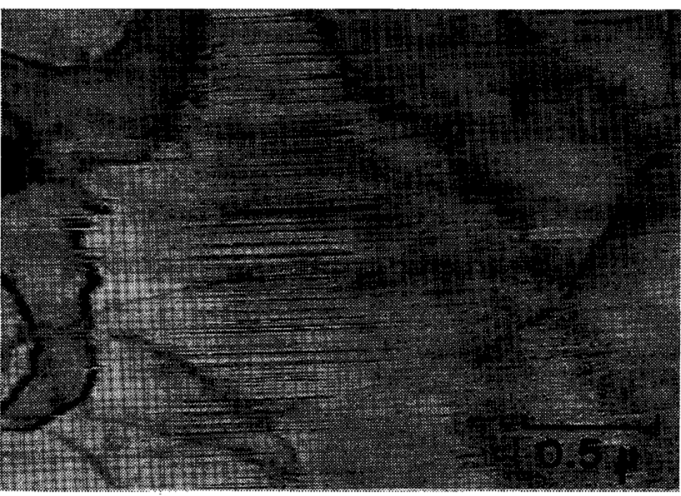

Photo. 2 Transmission electron micrograph showing lengthy twins extending through a "thin foil" martensite plate (Fe-6Mn-1C).

at low temperatures, and were not found in the $\mathrm{Fe}-\mathrm{Cr}-\mathrm{C}$ steel with an $\mathrm{M}_{\mathrm{s}}$ temperature close to room temperature. This effect is considered elsewhere ${ }^{(20)}$.

\section{Internal twins in martensite}

As with martensite formed in bulk specimens, numerous $\{112\}_{b}$ twins were observed in the thin foil martensites in the various materials studied. The twin morphology was, however, highly variable, ranging from lengthy twins extending through a martensite plate (Photo. 2), mixtures of long twins and twin segments (Photo. 3(a)), twin segments only (Photo. 4), and linear arrays of very fine twins (Photo.
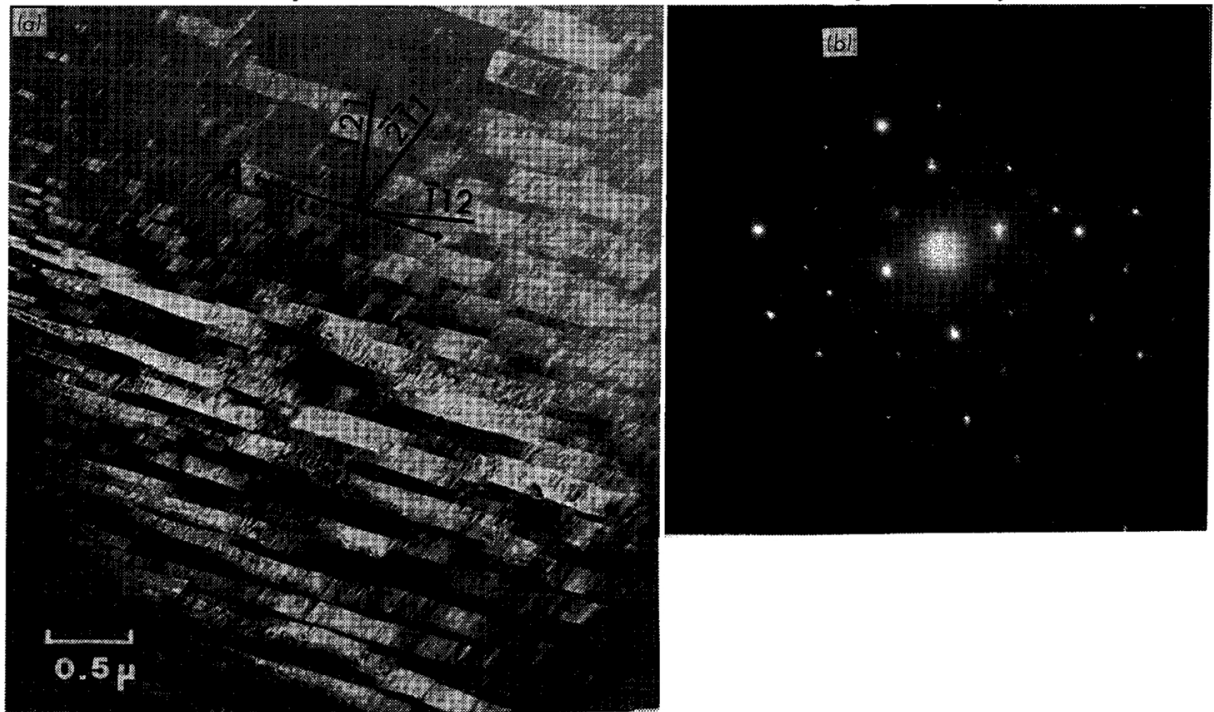

Photo. 3 (a) Dark field image taken from $\overline{1} 10$ twin reflection showing long twins and twin segments in $\mathrm{Fe}-6 \mathrm{Mn}-1 \mathrm{C}$ alloy.

(b) Selected area diffraction pattern taken from central region of (a). 


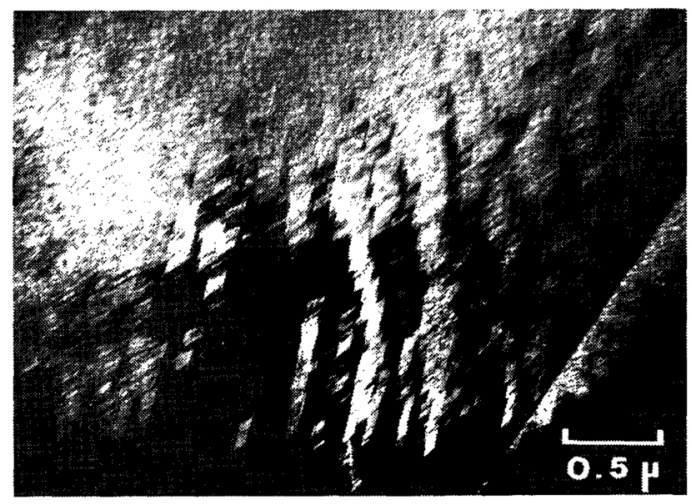

Photo. 4 Dark field image from twin reflection showing martensite plate containing only twin segments (Fe-3Mn-3Cr-1C).

8(a)). In Photo. 2, the observed striations are shown to be twins from the diffraction pattern. In all other cases dark field images using a twin diffraction spot have been used to reveal the various morphologies, details of which are now considered.

Photograph 3(b) is a diffraction pattern taken from the central region of Photo. $3(\mathrm{a})^{\dagger}$. Because of specimen buckling due to transformation strains, diffraction spots characteristic of several zones appear in the diffraction pattern, as shown in the index diagram, Fig. 1. The diffraction pattern can, however, be explained on the basis of $\{112\}_{b}$ twinning as follows.

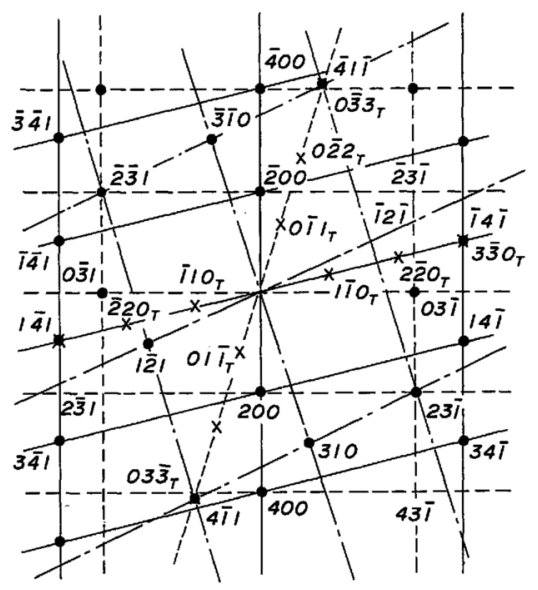

Fig. 1 Index diagram for Photo. 3(b) showing the presence of 014,013 , and 137 matrix zones and $\overline{2} \overline{2} \overline{3}$, $\overline{4} \overline{5} \overline{7}$, and $\overline{3} \overline{5} \overline{5}$ twin zones.

$\dagger$ All diffraction patterns have been rotated into proper orientation with respect to the image.
Using [014] as the beam direction, the same diffraction pattern is obtained for any of the (211), (121) and (112) twin planes, the twinning direction being [1111]. However, trace $\mathrm{A}$ in Photo. 3(a) is not coincident with any of these twinning planes. A similar discrepancy was reported by Shimizu for $\mathrm{Fe}-\mathrm{Ni}$ martensites ${ }^{(21)}$, who found deviations from the ideal $\{112\}_{b}$ trace up to 21 degrees. According to Shimizu, the deviation varies from plate to plate, but is constant in a given plate. It was suggested that the deviation resulted a "post transformation" shearing of the twins. Patrician et al. ${ }^{(22)}$ also observed such deviations in Fe-Ni alloys and proposed that the discrepancy arises from buckling in the specimen which causes a deviation between the "real" and "apparent" traces, which could be as large as 46 degrees. The present experiments clearly indicate the importance of buckling, at least for specimens transformed in the thin foil condition, and consequently attention to this was required in carrying out trace analyses.

Photographs 5 and 6 are presented as examples used to check the possible importance of film buckling. The diffraction pattern, Photo. 5(b) shows both [111] and [115] zones $^{\dagger \dagger}$,

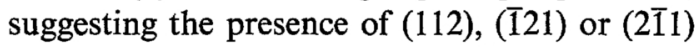
twins (with twinning direction [111]). The twins are clearly seen in Photo. 5(a) which is a dark field image taken using the $(0 \overline{1} 1)$ twin reflection. Possible twin traces are indicated in Photo. 5(a) by arrows. When the specimen is tilted $^{\dagger \dagger}$ to an orientation which includes the [011] and [101] zone axes (away from the initial orientation containing the [115] and [111] zone axes, respectively), the resulting images and diffraction pattern are shown in Photo. 6. As a consequence of the reorientation, the (112), (121) and (2ז1) poles move as shown in Fig. 2. The final position of these poles lies on a great circle with zone axis [111]. In this case, as is seen the twin trace cannot be $B$ and must correspond to $\mathrm{A}$ for any of the three twinning planes. This is contrary to previous investigations $^{(21)(23)}$ in which the twinning plane was taken as trace $B$ because the plane defined by

$\dagger \dagger$ [113] zone is also seen. This appears due to foil buckling.

$+\dagger \dagger$ Tilting angle was between $-20^{\circ}$ and $+20^{\circ}$. 

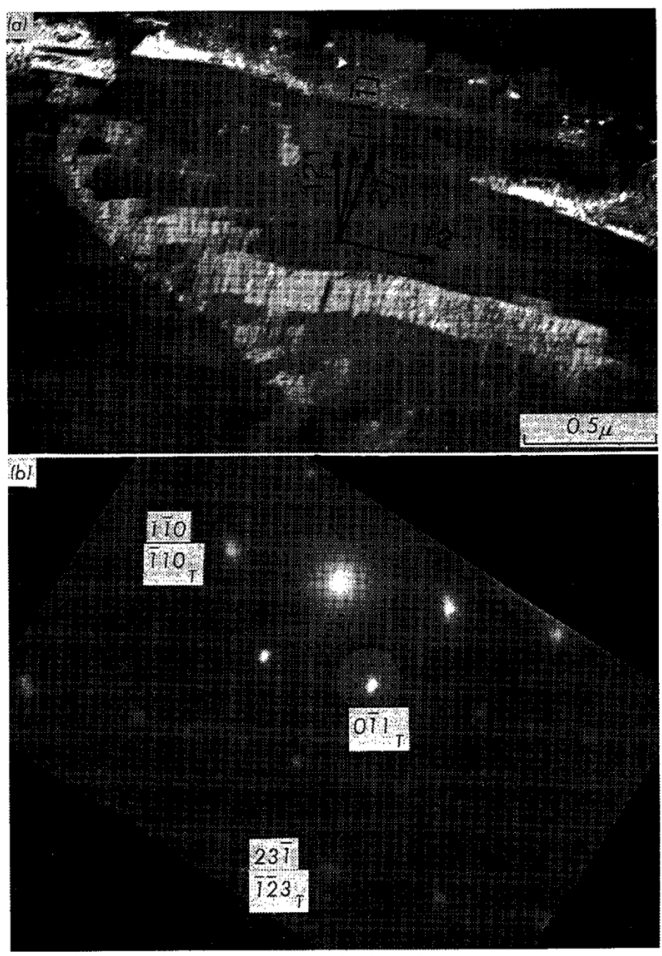

Photo. 5 (a) Dark field image from $0 \overline{1} 1$ twin reflection $(\mathrm{Fe}-6 \mathrm{Mn}-1 \mathrm{C})$.

(b) Selected area diffraction pattern from central region of (a). The electron beam is parallel to $[115]_{\text {matrix }}$ and $[111]_{\text {twin. }}$.

trace $B$ showed a fringe contrast parallel to the specimen plane, indicative of a planar interface.
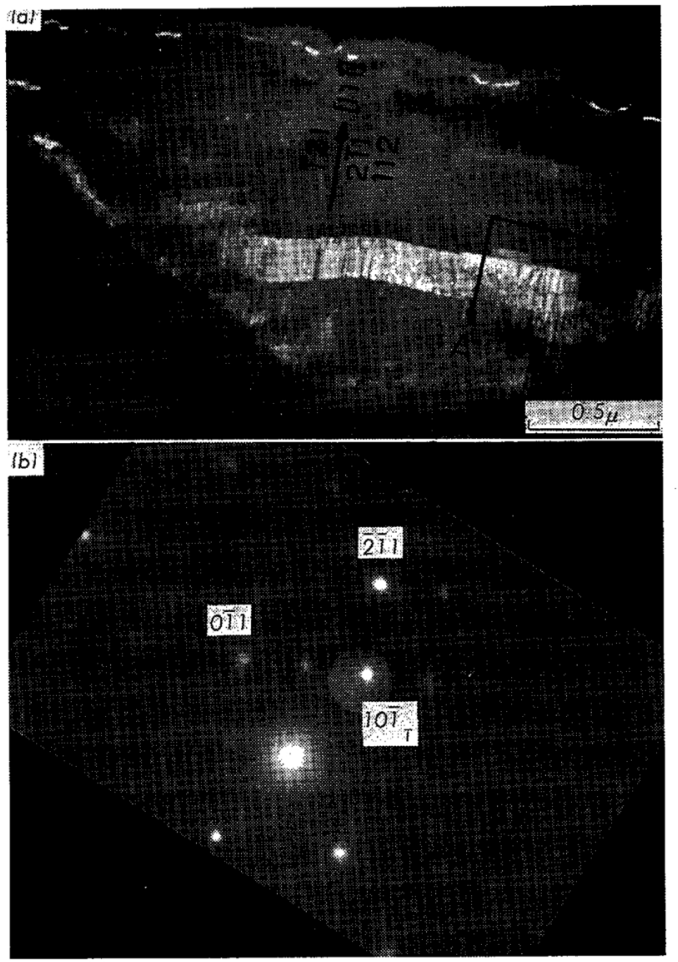

Photo. 6 (a) Dark field image from $10 \overline{1}$ twin reflection.

(b) Selected area diffraction pattern from central region of (a). The electron beam is parallel to $[011]_{\operatorname{matrix}}$ and $[101]_{\text {twin }}$.

Thus, the question arises, considering Photos. 5 and 6 , as to the nature of trace B. Considering
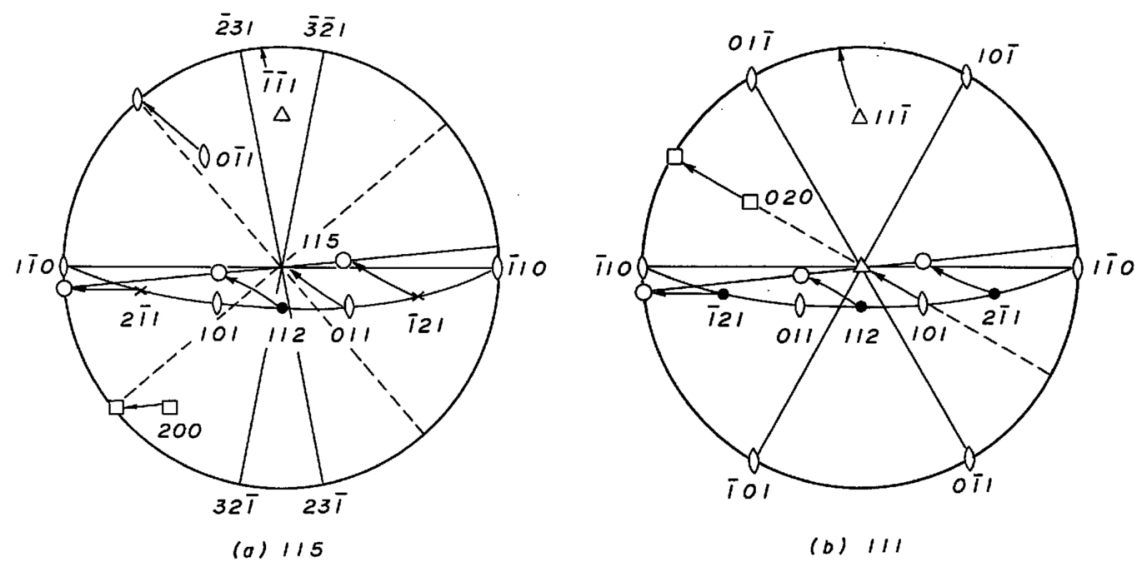

Fig. 2 Stereographic projection showing the movement of plane normals when the specimen is tilted. Before tilting the beam direction is parallel to [115] $]_{\text {matrix }}$ and [111 $]_{\text {twin }}$; after tilting, the beam is parallel to $[011]_{\text {matrix }}$ and $[101]_{\text {twin }}$. 
that the projected width of the observed twins is essentially constant, trace B should correspond to an important crystallographic plane. Nevertheless, the indexing of this plane is not clear. Naturally, if A represents a surface trace, B must correspond to an "internal" trace, and vice versa. Thus, the interpretation of the actual

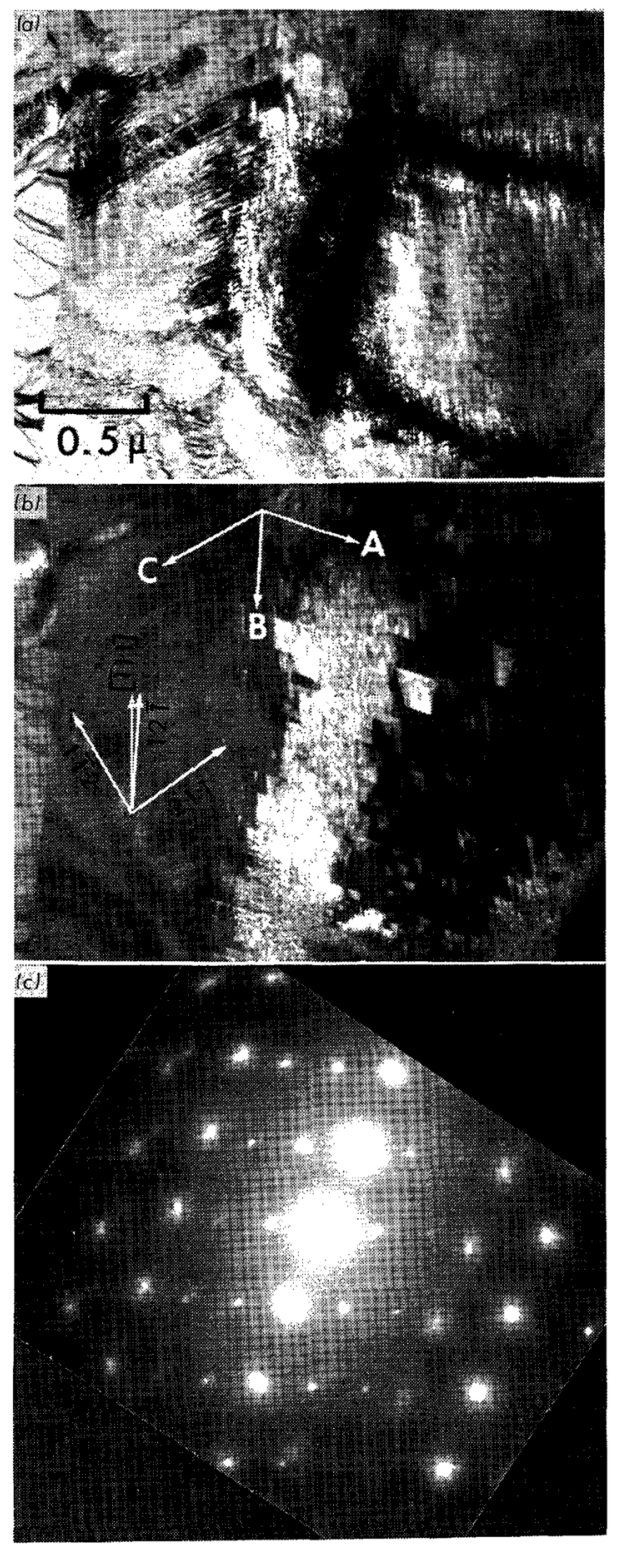

Photo. 7 (a) Bright field image of midrib region in $\mathrm{Fe}-6 \mathrm{Mn}-1 \mathrm{C}$ thin foil martensite plate.

(b) Dark field image using 011 twin reflection.

(c) Selected area diffraction pattern obtained from midrib region (see Fig. 3). twinning plane is not straightforward.

Photograph 7 is another example which emphasizes the difficulty in determining the actual twinning plane. The corresponding diffraction pattern, Photo. 7(c) shows a number of zones, i.e., [112], [113], [721], [511], etc. Despite the variety of zone axes, if the incident beam is taken as [112] with respect to a matrix, the entire pattern can be explained by taking the

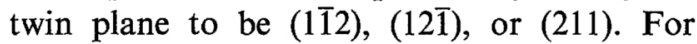

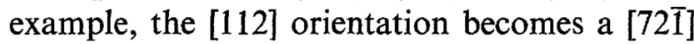
orientation as a result of (211) twinning. However, the [72i] pattern is coincident with the [112] pattern as shown in Fig. 3 in which case no additional twin reflections are revealed. A close inspection, however, shows that twin spots are indeed seen in the diffraction pattern. These are identified with the [511] zone which appears because the angle between [721] and [511] is only five degrees. As seen from the dark field image obtained using the 011 reflection from the [51]] zone (Photo. 7(b)), many twin segments are observed to be concentrated at the martensite midrib region. It was found, however, that trace A does not correspond with $(1 \overline{1} 2),(12 \overline{1})$ or (211). On the other hand, direction $B$ is very close to [111] and nearly corre-

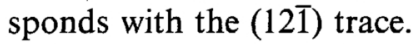

A procedure was adopted to determine the lattice plane of a trace as observed in a twinned crystal (i.e., matrix and twin orientations). Two stereographic projections were made by bring-

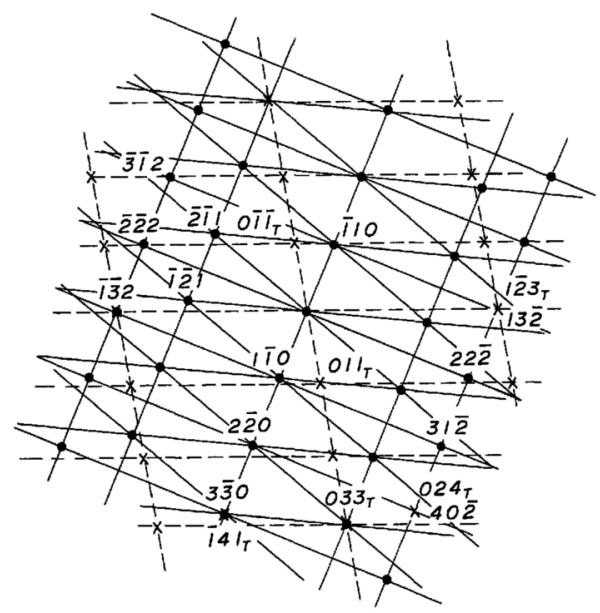

Fig. 3 Index diagram for Photo. 7(c). The electron beam is parallel to [112] and [113] of the matrix, and [721] and [511] of the twin. 
ing both the twin and matrix orientations into the plane of projection. Neglecting small differences due to tetragonality, both projections were superimposed, and certain low index plane normals common to both orientations were coincident. Such overlapping planes were crystallographic variants, with a common $\{h k l\}$ index. If it is assumed that trace $\mathrm{A}$ is common to both the matrix and twinned regions, the most likely choice becomes (101). For trace C, possible planes are (312) or (211).

\section{Fine twins}

Highly segmented twins, almost rod-like in nature, are frequently observed as shown in Photo. 8(a) for an Fe-6Mn-1C alloy. Such twins (as verified by dark field images) appear to be arranged quite regularly in bands; within a band, the separation of the twin segments is on the order of $100 \AA$. The diffraction pattern from the twinned region of Photo. 8(a) is shown in Photo. 8(b). Taking the inci-
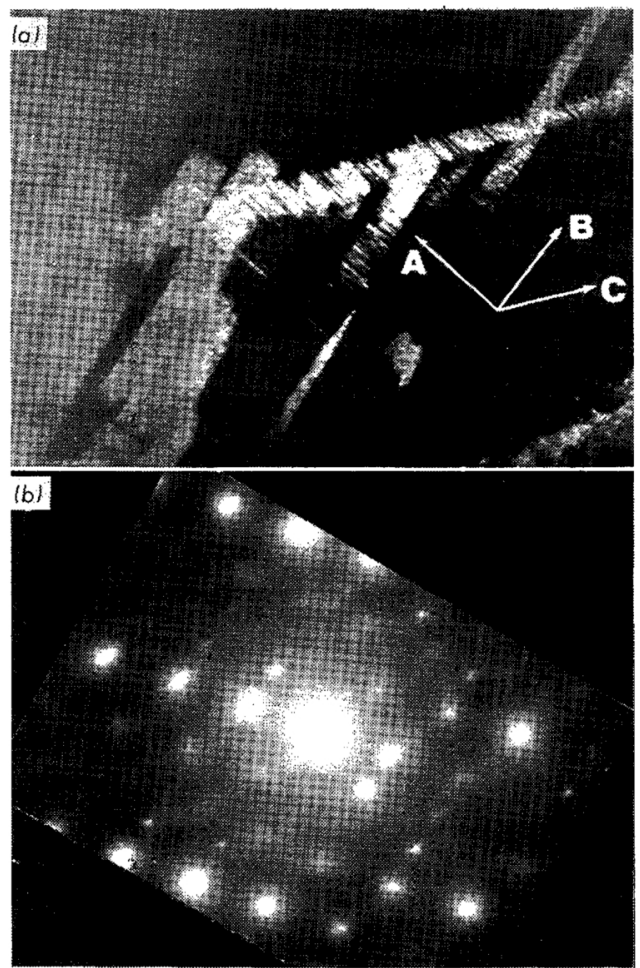

Photo. 8 (a) Dark field image using 011 twin reflection showing very fine twins.

(b) Selected area diffraction pattern from the finely twinned region of (a).

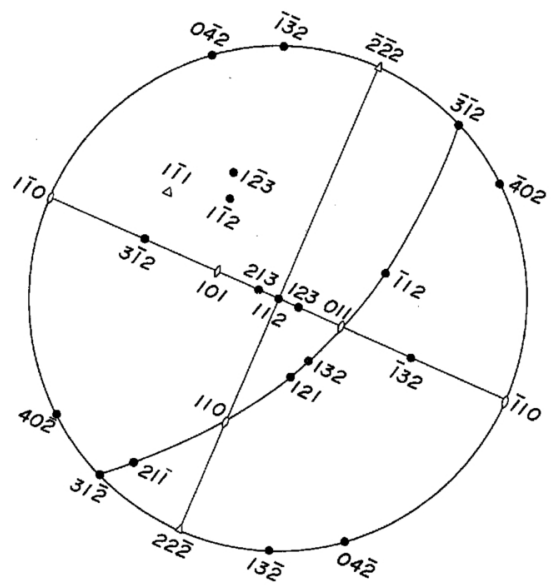

Fig. 4 (112) stereographic projection giving analysis of Photo. 8.

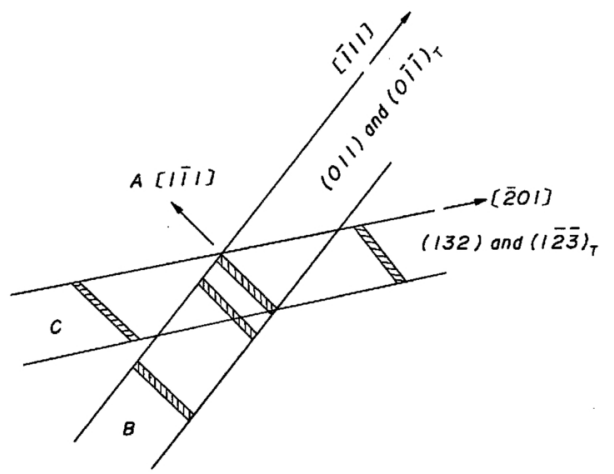

Fig. 5 Schematic description of twin segments shown in Photo. 8.

dent beam direction as [112], possible twinning planes are (112), (121) or (211). The direction A corresponds to [111]. As seen from the stereographic projection, Fig. 4, possible traces for B and $\mathrm{C}$ include:

Trace B: $123,213,011,101, \overline{1} 32$ or $3 \overline{1} 2$;

Trace C: $132,1 \overline{1} 2$ or $1 \overline{2} 3$.

Considering that the fine twin segments appear to be situated at the intersection of bands $B$ and $\mathrm{C}$, and that their direction is [111] the most probable planes for traces $\mathrm{B}$ and $\mathrm{C}$ are respectively (011) and (132). The intersection of these planes is given by [ $[\overline{1} 1 \overline{1}]$ which is consistent with the observed direction. Considering the faint streaks observed in the diffraction pattern,

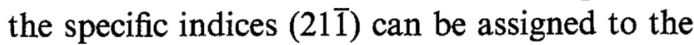
twinning plane. Further, the direction of trace B is given by the intersection of the (112) surface 

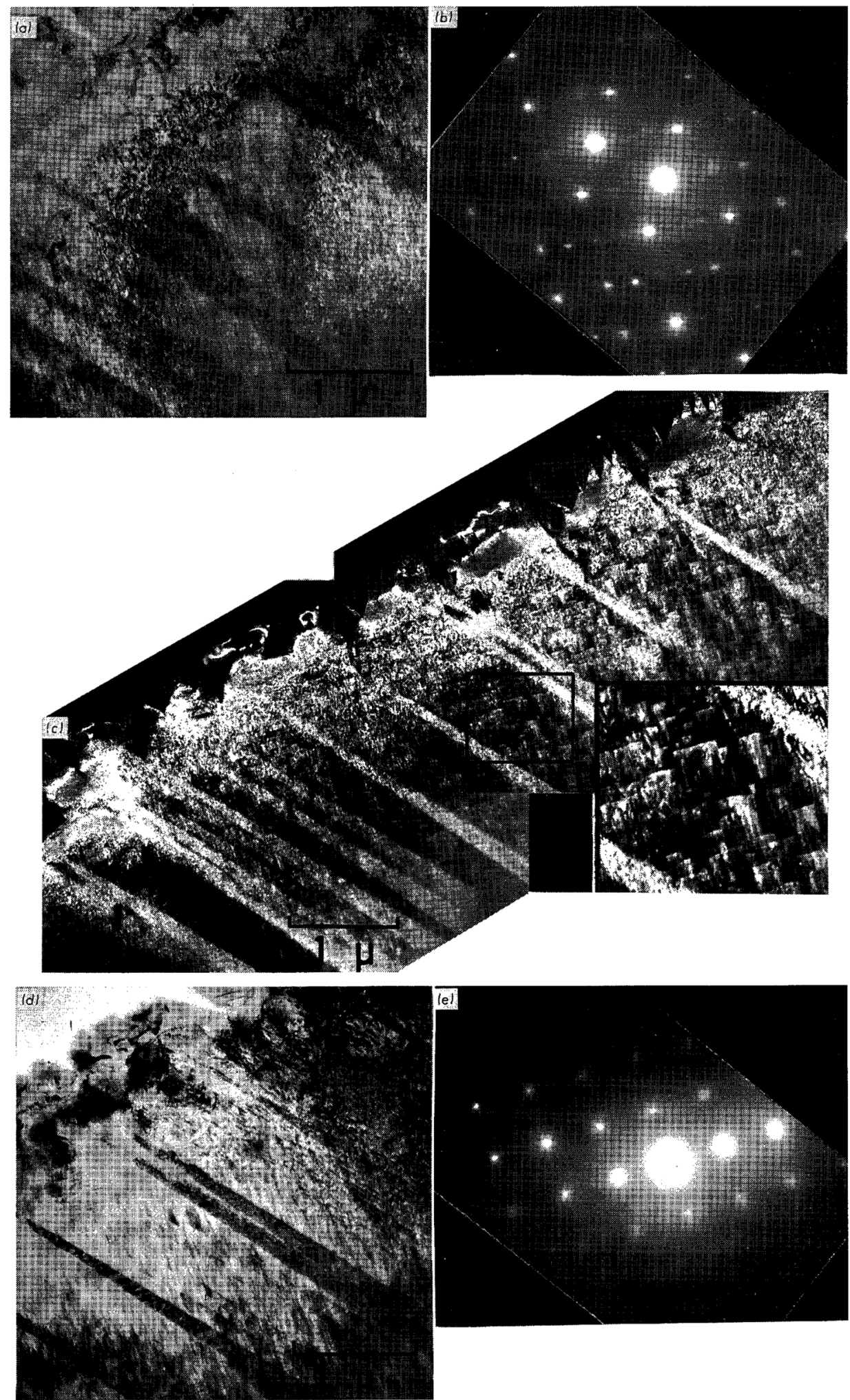

(Photo. 9) 


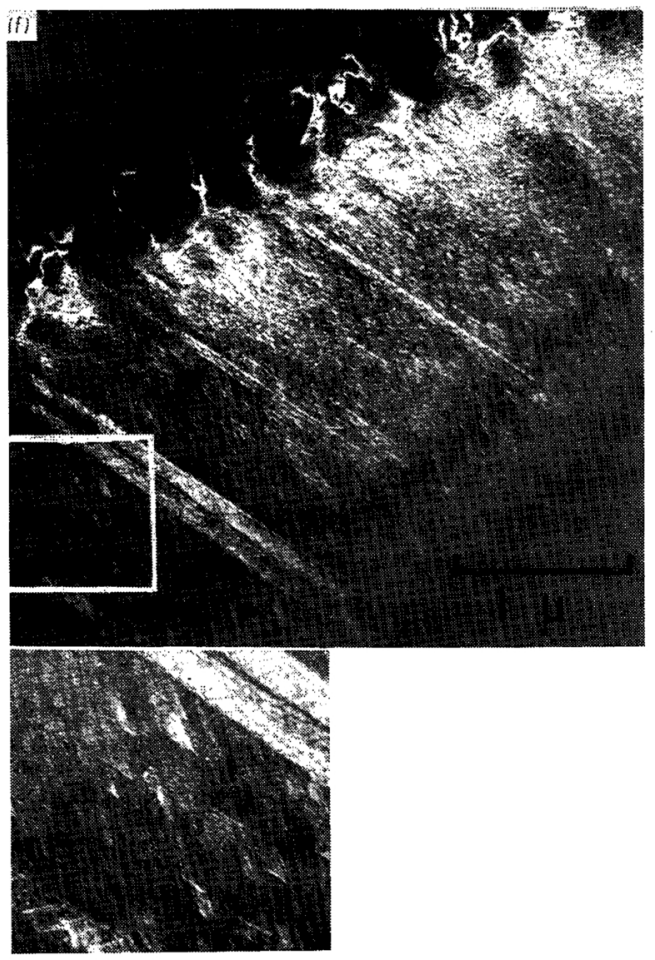

Photo. 9 (a) Bright field image showing fine striations within parallel bands and high dislocation density (Fe-6Mn-1C).

(b) Selected area diffraction pattern taken from the banded region in (a).

(c) Dark field image taken from 110 twin reflection.

(d) Bright field image taken after tilting from orientation shown in (a).

(e) Selected area diffraction pattern from (d).

(f) Dark field image taken using 110 matrix reflection.

and (011), which is [111]. Similarly, considering the direction of trace $\mathrm{C}$ and the surface plane, the intersection is [201]. For a cubic structure, the angle between [111] and [201] is $39^{\circ} 14^{\prime}$, which is very close to the observed angle of 40 degrees.

The analysis just presented is also supported by physical considerations. For example when $(21 \overline{1})$ twins are introduced, the twinning operation carries $(011)$ to $(0 \overline{1} \overline{1})_{T}$ and $(132)$ to $(1 \overline{2} \overline{3})_{T}$. Thus the before and after positions are parallel and straight traces would be measured, which is the case. This is shown schematically in Fig. 5.

A further example of finely segmented twins is shown in Photo. 9. In the bright field image (Photo. 9(a)) fine striations with separation about $100 \AA$ are observed to be situated within parallel bands; a high density of dislocations within the martensite plate is also seen. From the dark field image, Photo. 9(c), taken by using a $(1 \overline{1} 0)$ twin reflection, the twins are revealed to be concentrated within bands, although some scattered twins between the bands are also seen. Upon tilting the same specimen area from an [014] (Photo. 9(b)) to an [001] orientation (Photo. 9(d)) the width of the bands containing the fine twins decreases, and from an analysis of the projected width of the bands, it is concluded that the band trace corresponds to (011). In several cases it was inferred that the (011) bands were derived from $\{111\}_{f}$ stacking faults, but this remains to be proven.

Analysis of the diffraction pattern (Photo. 9(b) and Fig. 6) suggests that possible twin planes are (112), (121) and (211), and that the twinning direction is [111]. Considering the faint streaks seen in Photo. 9(b), and the elongated diffraction spots, the most reasonable choice is $(\overline{21} 1)$. The situation is crystallographically similar for Photo. 8. On the other hand, the twin segments between bands exhibit rather random shapes and sizes, and the crystallographic features are not clear. Upon tilting the specimen, many stacking fault-type fringes are seen, which are parallel to the bands of twin concentrations, as shown in Photo. 9(f). Com-

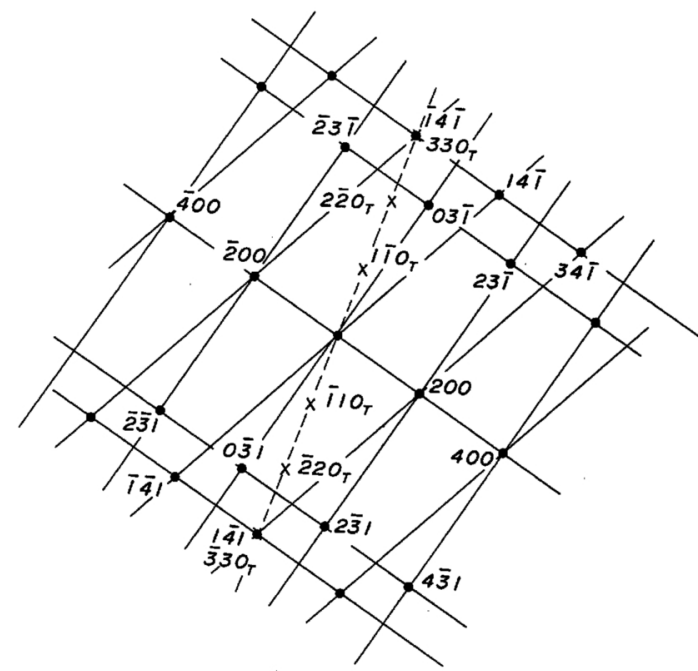

Fig. 6 Index diagram for Photo. 9(b). 
paring corresponding regions (framed areas) in Photos. 9(d) and 9(f), it is inferred that the observed stacking fault fringes are related to the concentration of twins within bands.

Photograph 10 indicates a relationship between $\{111\}_{f}$ stacking faults in austenite and $\{112\}_{b}$ twins in martensite. In the retained austenite, near the edge of the thin foil specimen, $\{111\}$ planar faults are observed; and in the marteniste, twin fragments are seen which appear to be morphologically related to the $\{111\}$ faults.

Thus although a number of examples, considering the present results, suggest that apparent twin traces do not coincide with the ideal $\{112\}$ traces, a clear relationship does appear to hold, considering the twin traces and $\{011\}_{b}$ and/or $\{123\}_{b}$ planar faults. The previous discussion makes it clear that ambiguities in interpretation can result from buckled specimens in which case the specimen surface may not be perpendicular to the electron beam. An attempt was thus made to remedy this difficulty by the use of a "standard" specimen. Photograph 11 is an example. Photograph 11(a) shows a retained austenite region immediately adjacent to a martensite plate which exhibits two stacking fault traces. The diffraction pattern taken from this region, Photo. 11(b), indicates a [110] orientation, and trace analysis of the stacking fault planes proves them to be exactly coincident with $\{111\}$ planes. This indicates that the specimen normal in this case is exactly parallel to the electron beam. Photograph 12(a)

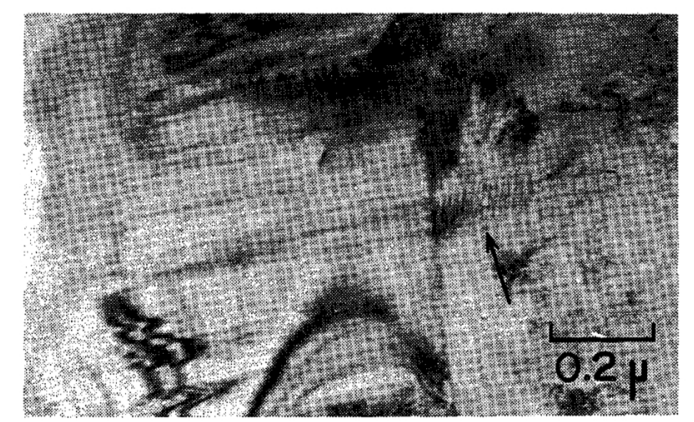

Photo. 10 Transmission electron micrograph showing apparent relationship between $\{111\}$ austenite stacking fault and segmented $\{112\}$ twins in martensite for $\mathrm{Fe}-6 \mathrm{Mn}-1 \mathrm{C}$ alloy (indicated by arrow).
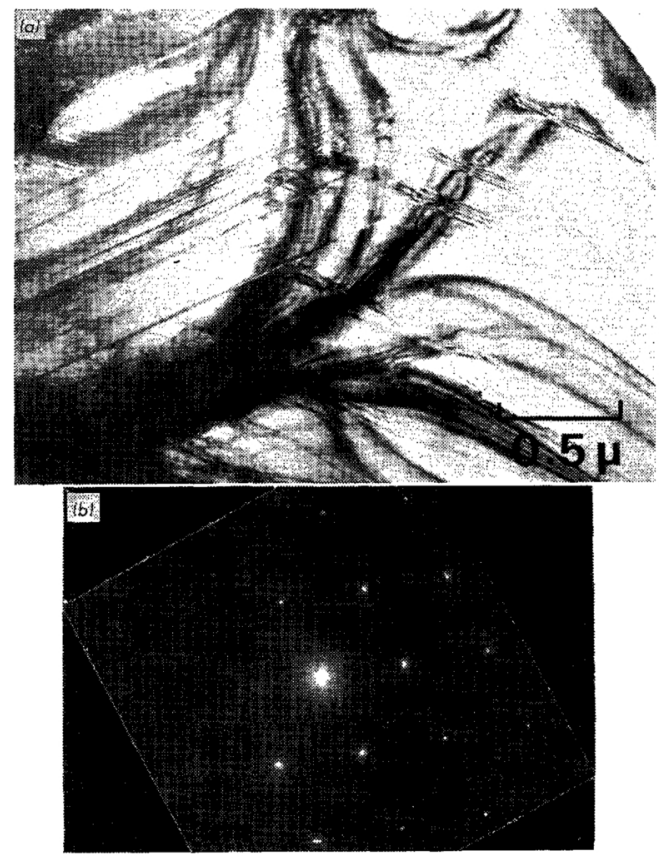

Photo. 11 (a) Transmission electron micrograph showing $\{111\}$ stacking fault traces in austenite.

(b) Selected area diffraction pattern from (a).

is a martensite plate immediately adjacent to the region shown in Photo. 11. Two prominent traces are seen within the plate. Trace a is very close to (101) and trace b corresponds to [1111]. These results are the same as those deduced previously. A careful examination of Photo. 12(a) shows that a third trace can be found, which is defined by isolated twins (encircled region). This trace, designated $\mathrm{c}$, is coincident with (211). This is an important result, and suggests the interpretation presented in Fig. 7 accordingly the image of a twin segment is considered to be defined by an $\{011\}$ planar fault and a $\{112\}$ twin. If the $\{011\}$ fault is thin and if the twin density is significant, the image is expected to resemble that shown in the lower part of Fig. 8.

It is possible that the $\{011\}$ planar faults, which define the twins discussed in the previous paragraph, are inherited from $\{111\}$ austenite stacking faults. However, the origin of the $\{123\}$ type bands as seen in Photo. 8 is yet unclear. From the Bain correspondence, $\{123\}_{b}$ is derived from $\{115\}_{f},\{133\}_{f}$ or $\{244\}_{f}$, all of which contain the close-packed direction 


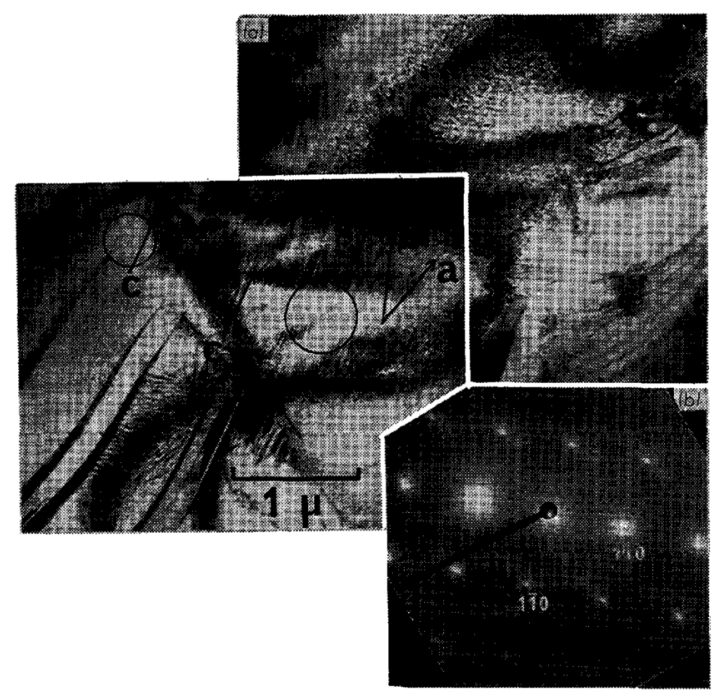

Photo. 12 (a) Transmission electron micrograph of thin film martensite plate in $\mathrm{Fe}-6 \mathrm{Mn}-1 \mathrm{C}$ showing three prominent traces.

(b) Selected area diffraction pattern from (a). Beam direction approximately parallel to [001].

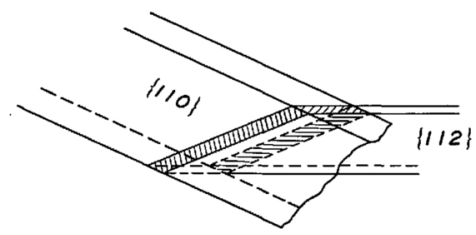

Fig. 7 Schematic representation of the intersection of a $\{112\}_{b}$ twin and $a\{011\}_{b}$ fault.

$\langle 110\rangle_{f}$. This may indicate that in addition to $\{112\}\langle 111\rangle_{b}$ twinning, the system $\{123\}$ $\langle 111\rangle_{b}$ is also a part of the transformation inhomogeneous shear.

Shimizu, Oka and Wayman ${ }^{(24)}$ observed small plates of martensite in an $\mathrm{Fe}-8 \mathrm{Cr}-1 \mathrm{C}$ steel quenched to just below the $M_{s}$ and found stacking faults "associated" with martensite plates, thus implying the possibility that austenite stacking faults were nucleating sites. However, it was also argued that the associated faults could have resulted from accommodation stresses due to the interaction of the austenite matrix with the martensite shape strain. There are further reports ${ }^{(25)(26)}$, for the case of stress-induced martensite in austenite of low stacking fault energy, that faulted austenite (i.e., the $h c p \quad \varepsilon$ martensite provides favorable nucleation sites for the formation of $b c c$

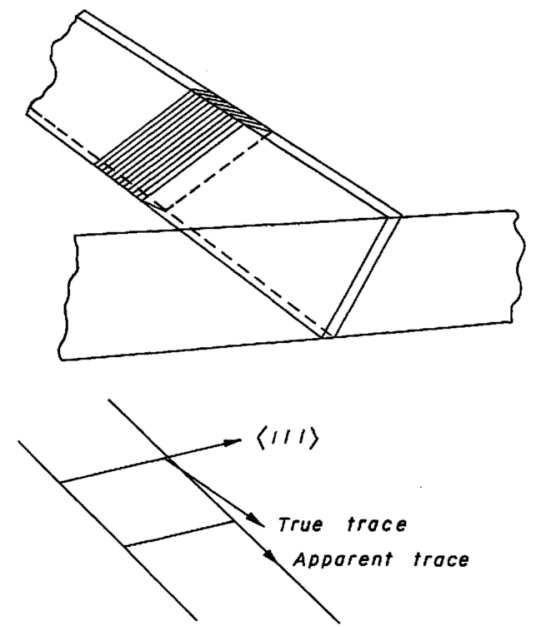

Fig. 8 Schematic drawing showing possible difference between apparent and true twin traces.

martensite). In the present experiments as well, a high density of segmented twins in $\{011\}_{b}$ bands indicates that $\{111\}_{f}$ faults play an important role in the transformation.

Lysak et al. ${ }^{(17)}$ recently suggested that the formation of bct martensite in a $\mathrm{Fe}-\mathrm{Mn}-\mathrm{C}$ steel occurs through an intermediate hexagonal phase which is the first to form from the austenite. No results from the present work were obtained which would support such a model.

\section{4. $\{011\}_{b}$ and $\{123\}_{b}$ stacking faults and dislocations}

$\{011\}_{b}$ and $\{123\}_{b}$ stacking faults were also observed as internal inhomogeneities in martensite in some of the alloys studied. One relationship between $\{011\}$ faults and internal twins has already been discussed. In other cases, as shown in Photo. 13(a) and 13(b), short stacking faults showing characteristic fringe contrast are also observed. It is difficult to evaluate the origin of these faults. While the absence of constraints is expected in martensitic transformations in thin films, and hence it would appear that the $\{011\}$ and $\{123\}$ faults are intrinsic as regards the inhomogeneous shear of the transformation, the possibility of accommodation strains cannot be excluded. If the latter is so, the present observations indicate that $\{011\}$ and $\{123\}$ stacking faults may 
be intrinsic to deformation processes in $b c c$ (bct) materials. Whichever the case, the present observations substantiate the formation of faults on $\{011\}$ and $\{123\}$ planes.

Thomas et al. ${ }^{(13)}$ suggest that detwinning occurs in thin film martensites in $\mathrm{Fe}-\mathrm{Ni}-\mathrm{V}-\mathrm{C}$ and $\mathrm{Fe}-\mathrm{Ni}-\mathrm{C}$ alloys. They suggest that the fine striations observed within $\{112\}$ are due to detwinning. However, they observed striations in only the twin orientation and not in the matrix orientation, implying a highly specialized type of deformation. In this connection it is to be noted that slip on both $\{011\}$ and $\{123\}$ planes involving the close-packed $\langle 111\rangle$ slip direction can penetrate undeviated through $\{112\}$ twin related regions by the transfer of slip to other crystallographic variants of the slip system (i.e., $(101) \rightarrow(011)$ or $(123) \rightarrow(213))^{\dagger}$. Of the various $\{112\}_{b}$ deformation modes, only three variants with a common $\langle 111\rangle$ shear direction are "convertible". For example, in the case of (112) twinning a further twin (or

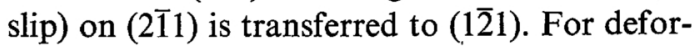
mation on $\{123\}_{b}$ six $\{123\}$ planes are transferable across $\{112\}$ twins. Similarly, four $\{011\}$ planes are convertible.

The previous comments show that $\{123\}$ $\langle 111\rangle$ and $\{011\}\langle 111\rangle$ systems exhibit more trans-twin deformation modes than $\{112\}$ twinning or detwinning. Furthermore, both $\{123\}$ and $\{011\}$ deformation modes are expected to occur in $\{112\}$ twinned martensite.

An example of a complex substructure is shown in Photo. 14 where traces A and B correspond to $\{011\}$ planar faults. Fine twins are also seen in.Photo. 14 (see arrow). Photograph 15 is another example of a complex internal structure. In this case planar defects on two $\{123\}$ planes are observed. Photograph 16 is an example of a dislocation structure which is elongated in $\langle 111\rangle$ directions. Similar $\langle 111\rangle$ arrays of dislocations have been observed in

$\dagger$ When the twinning plane is ( $p g r$ ) a lattice plane $(h k l)$ is transferred to $\left(h^{\prime} k^{\prime} l^{\prime}\right)$ according to

$$
\begin{aligned}
& h^{\prime}=\frac{p(p h+2 q k+2 r l)-h\left(q^{2}+r^{2}\right)}{p^{2}+q^{2}+l^{2}} \\
& k^{\prime}=\frac{q(2 p h+q k+2 r l)-k\left(p^{2}+r^{2}\right)}{p^{2}+q^{2}+l^{2}} \\
& l^{\prime}=\frac{r(2 p h+2 q k+r l)-l\left(p^{2}+q^{2}\right)}{p^{2}+q^{2}+l^{2}}
\end{aligned}
$$
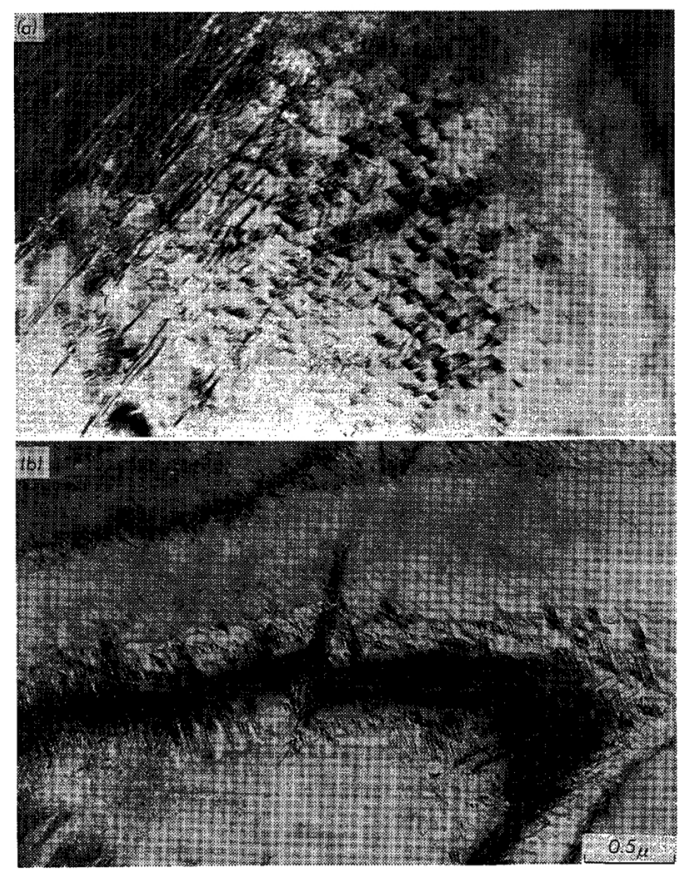

Photo. 13 Transmission electron micrograph of thin foil martensite plate in $\mathrm{Fe}-6 \mathrm{Mn}-1 \mathrm{C}$ alloy showing stacking fault fringe contrast. (a) $\{011\}$ faults and (b) $\{123\}$ faults.

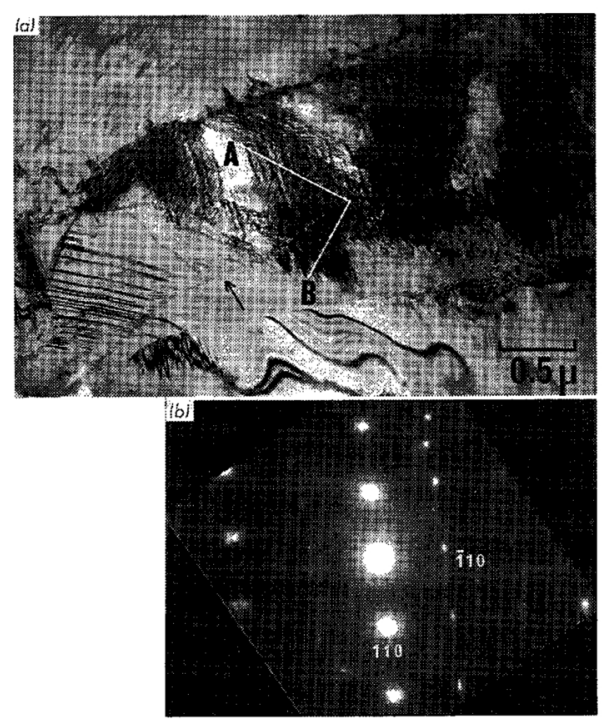

Photo. 14 Transmission electron micrograph showing complex intenal structure in thin foil martensite plate $(\mathrm{Fe}-6 \mathrm{Mn}-1 \mathrm{C})$ and corresponding selected area diffraction pattern. The electron beam is approximately parallel to [001]. 


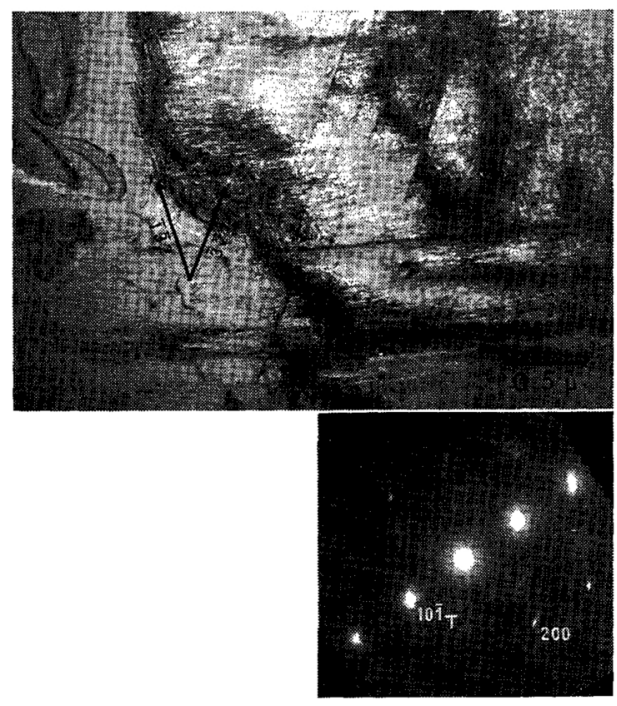

Photo. 15 Transmission electron micrograph showing complex substructure in thin foil martensite plate in $\mathrm{Fe}-6 \mathrm{Mn}-1 \mathrm{C}$, and corresponding selected area diffraction pattern. Beam direction $\approx[014]$.

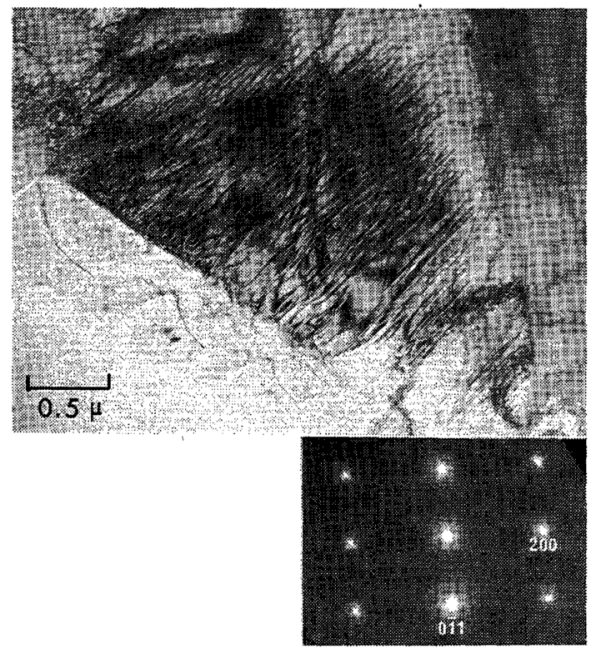

Photo. 16 Transmission electron micrograph of thin foil martensite in $\mathrm{Fe}-6 \mathrm{Mn}-1 \mathrm{C}$ alloy showing dislocations along $\langle 111\rangle$ directions, and corresponding selected area diffraction pattern. Beam direction $\approx[011]$.

martensite plates formed in bulk specimens ${ }^{(23)}$.

\section{Conclusions}

(1) The substructure of martensite formed in thin foils in $\mathrm{Fe}-6 \mathrm{Mn}-1 \mathrm{C}, \mathrm{Fe}-5.5 \mathrm{Mn}-1 \mathrm{C}$,
$\mathrm{Fe}-3 \mathrm{Mn}-3 \mathrm{Cr}-1 \mathrm{C}$, and $\mathrm{Fe}-8 \mathrm{Cr}-1 \mathrm{C}$ has been studied in detail using transmission electron microscopy and diffraction. In all cases, the $\mathbf{M}_{\mathbf{s}}$ temperature was below room temperature. As for bulk specimens, the habit plane in a number of cases was near $\{225\}_{f}$, but there were cases where the habit plane was not well defined, and in fact, not planar. The substructure in thin foil martensite was found to be highly complex, and indications of substantial accommodation deformation within the martensite plates were seen; this was not expected considering that constraints should be lessened considerably in two-dimensional thin foils.

(2) As with bulk martensite, $\{112\}_{b}$ twins, $\{011\}_{b}$ and $\{123\}_{b}$ planar faults, and dislocations were observed in thin foil martensites in the materials studied.

(3) The morphology of the $\{112\}_{b}$ transformation twins in a given material was found to be highly variable. The following morphologies were observed: (i) lengthy twins extending completely through a plate; (ii) mixtures of long twins and twin segments; (iii) only twin segments; and (iv) very fine twin segments.

(4) The apparent discrepancy between surface traces and possible traces of the $\{112\}_{b}$ twin planes was studied in some detail. Besides ambiguities due to specimen buckling, it was found that other (internal) traces, in contrast to the surface traces, may more properly describe the twin plane. In this respect, the present interpretation differs from previous ones. Very fine twin segments, with a regular spacing on the order of $100 \AA$ were found to be confined by $\{011\}_{b}$ and/or $\{123\}_{b}$ planar faults. The indicated crystallography between the twins and faults can also lead to a misinterpretation of the actual twin plane.

(5) A number of observations suggest that $\{011\}_{b}$ planar faults are inherited from $\{111\}_{f}$ austenite stacking faults. The origin of the $\{123\}_{b}$ faults is not as clear. It is, however, significant that the observed $\{011\}_{b}$ and $\{123\}_{b}$ stacking faults are those particular variants which are capable of penetrating both $\{112\}$ orientations of the transformation twins, indicating that the faults may occur after $\{112\}$ twinning and hence plate formation.

(6) The observation of short lengths of 
$\{011\}_{b}$ and $\{123\}_{b}$ stacking faults in martensite may indicate that other inhomogeneities (besides $\{112\}_{b}$ twins) are involved in the formation of $\{225\}_{f}$ plates.

\section{Acknowledgment}

This work was sponsored by the U. S. Army Research Office (Durham). Their support is gratefully acknowledged.

\section{REFERENCES}

(1) M. S. Wechsler, D. S. Lieberman and T. A. Read: Trans. AIME, 197 (1953), 1503.

(2) J. S. Bowles and J. K. Mackenzie: Acta Met., 2 (1954), 129, 138, 224.

(3) R. Bullough and B. A. Bilby: Proc. Phys. Soc., B LXIX, (1956), 1276.

(4) D. P. Dunne and C. M. Wayman: Met. Trans., 2 (1971), 2327.

(5) A. G. Crocker and B. A. Bilby: Acta Met., 9 (1961), 678.

(6) D.S. Lieberman and R. Bullough: Phys. Status Solidi, 12 (1965), 657.

(7) M. Oka and C. M. Wayman: Trans. ASM, 62 (1969), 370.

(8) V. I. Izotov and L. M. Utevsky: Fiz. Metal. Metalloved., 25 (1968) 98.

(9) K. Shimizu, M. Oka and C. M. Wayman: Acta Met., 19 (1971), 1.
(10) P. M. Kelly: Acta Met., 13 (1965), 635.

(11) S. Jana and C. M. Wayman: Met. Trans., 1 (1970), 2825.

(12) W. Pitsch: Phil. Mag., 4 (1959), 577.

(13) G. Thomas: Met. Trans., 2 (1971), 2373.

(14) L. I. Lysak, Ya. N. Vovk and Yu. M. Polishchuk: Fiz. Metal. Metalloved., 23 (1967), 898.

(15) Yu. A. Alshevski and G. V. Kurdyumov: Fiz. Metal. Metalloved., 25 (1968), 172.

(16) L. I. Lysak and L. O. Andrishchuk: Fiz. Metal. Metalloved., 28 (1968), 348.

(17) L. I. Lysak and B. I. Nikolin: Fiz. Metal. Metalloved., 20 (1965), 547.

(18) R. Oshima and C. M. Wayman: Met. Trans., 5 (1974), 1943.

(19) I. Cornelis, R. Oshima, H. C. Tong and C. M. Wayman: Scripta Met., 8 (1974), 133.

(20) R. Oshima and C. M. Wayman: Scripta Met., 8 (1974), 223.

(21) K. Shimizu: J. Phys. Soc. Japan, 17 (1962), 508.

(22) T. J. Patrician, H. M. Ledbetter and R. P. Reed: Met. Trans., 3 (1972), 947.

(23) R. L. Patterson and C. M. Wayman: Acta Met., 14 (1966), 347.

(24) K. Shimizu, M. Oka and C. M. Wayman: Acta Met., 18 (1970), 1025.

(25) J. A. Venables: Phil. Mag., 7 (1962), 35.

(26) G. B. Olson and M. Cohen: J. Less-Common Metals, 28 (1972), 107. 